\title{
HURRICANE HARVEY UNSTRAPPED: EXPERIENCING ADAPTIVE TENSIONS ON THE EDGE OF CHAOS
}

\author{
MAGDALENA ANNA DENHAM \& NATALIE BAKER \\ Department of Security Studies, Sam Houston State University, USA
}

\begin{abstract}
This paper is based on the analysis of data collected as part of a research conducted through National Science Foundation (NSF) grant 1760504 - RAPID: Disaster Preparedness and Response within Communities Affected by Hurricane Harvey. Our co-autoethnographic study focused on response and short-term recovery in Hurricane Harvey. It consisted of in-depth interviews conducted with emergency management officials, first responders, members of non-governmental organizations, civic leaders, spontaneous volunteers, and flooding victims coupled with an analysis of Crowdsource (spontaneously created virtual platform for citizens' response) data. Our results point to the phenomenon of unstrapping identified across standard operating procedures, organizational arrangements, formal communication flows, formal emergency management processes, and resource utilization protocols. While unstrapping has been evidenced in our study to be perceived as threatening by emergency management and response entities, we adapt a complexity-informed worldview to propose unstrapping representing natural processes inherent to complex adaptive systems. Our study highlights unpredictability and change in human and organizational systems and give rise to self-organization, self-regulation that ultimately gives rise to resilience and adaptability. Implications for emergency management and policy are
\end{abstract} discussed.

Keywords: emergency management, disaster preparedness, complex adaptive systems, response, short-term recovery, resilience, Hurricane Harvey, emergence, self-organization, co-autoethnography.

\section{INTRODUCTION}

Between 25th and 31st August 2017, the contiguous United States recorded unprecedented total rainfall from the tropical cyclone (TS) formation referred to as Hurricane Harvey (HH). In fact, "Harvey was the most significant tropical cyclone rainfall event in United States history, both in scope and peak rainfall amounts, since reliable rainfall records began around the 1880s" [1]. With the highest peak recoded at 60.58 inches in Nederland, Texas [1], Harvey dumped 1.2 trillion gallons of water on Harris County alone at an average of 40 inches of rain (more than average annual accumulation in the US for the year [2]). The Harris County Flood Control District (HDFCD) estimated 70\% of Harris County was flooded by at least 1.5 feet of water as of 31st August. Moreover, of the 154,170 homes flooded, 105,340 (i.e. $68 \%$ ) were outside the $1 \%$ (100 year) floodplain. There were 36 confirmed deaths [3].

Other areas such as Montgomery County (administrative zone north of Houston added to the Presidential Disaster Declaration on 30th August 2017) received an average of 26-30 inches of torrential rain. In low-lying county areas where an average of 100-137 homes have flooded in the past during significant torrential downpours (some of them more than 7 or 8 times), Harvey destroyed hundreds more that never flooded before. Homes in a River Plantation (RP) community received from 12-14 feet of water. "Unfortunately, a lot of those homeowners had no flood insurance because they never had to worry about [flooding] before" [4]. There were five storm-related deaths reported in Montgomery County. In a more rural and isolated Liberty County east of Houston gauges recorded 51 inches of rainfall [5]. The town of Liberty was battered with 32 inches rainfall in a 24 hour period between Saturday 26th August and Sunday 27th August. Resultant record river levels from San Jacinto River 
tributaries caused flooding in Cleveland, Williams, and Plum Grove; more than 7,000 homes were affected in Liberty County, but no deaths were reported [6].

Research on Texas flooding [7], [8] supports that anthropogenic factors such as urban development, floodplain encroachment, increased impervious cover, reduced overland and channel roughness, decreased storage ability and resource withdrawal have contributed to increasing flooding vulnerabilities. Not surprisingly, the U.S. Army Corps of Engineers predicted on 25th August that Barker and Addicks reservoirs would spill beyond government owned land flooding residential areas. Flooding advisories were not issued in Fort Bend County (south of Houston) until 26th August and Harris County until 27th August when some neighbourhoods were already inundated and reports estimating 4,000 homes and businesses flooded upstream of Barker and 5,000 to 6,000 upstream of Addicks [9]. In Montgomery County San Jacinto River Authority authorized unprecedented amount of water release from lake Conroe to prevent a dam breach. The released water travelled with unparalleled speed of 79,000 cubic feet per second and caused flooding in five large Montgomery County neighbourhoods (McDades Estates, River Plantation, Woodhaven Forste, Artesian Forest, Riverbrook Drive and Riverbrook Circle [10]).

Similarly, when officials opened the gates at Lake Livingston to release into the Trinity River, they unleashed a 5 foot wall of water 15 miles south of Liberty. Mandatory evacuations were ordered in both Montgomery and Liberty Counties on 28th August. Officially, Montgomery Fire Department reported 20 high water rescues in Conroe area and 111 rescues started by emergency responders in tributaries along and near Lake Conroe in Willis were noted [11]. In Harris County alone the government engaged in 60,049 rescues [5]. However, "the widespread flooding necessitated 120,000 rescues exceeding the capacity of formal emergency response organisations and requiring assistance of volunteers with access to boats and large vehicles" [12, p. 2]. In fact, it was the efforts of spontaneous and emergent social rescue activity that served as cues to Harris County fire and rescue officials to switch from emergency modes to disaster operations between Saturday night 26th August and Sunday 27th August. It is noteworthy that Harvey was one of the only flood events where a few people drowned in their home or workplace [3]. It is also important to note that while Harvey was unprecedented, researchers predict large scale weather events to become increasingly frequent and impactful due to anthropogenic changes [12]. It is against the backdrop of a biblical proportions rainfall, catastrophic and/or fast releases of water reservoirs, challenges of build urban environment (Houston), chronic flooding vulnerabilities and isolation of rural communities (Montgomery and Liberty Counties), that we have conducted this research. Our experiences come from those three counties where we were personally involved in disaster response and short-term recovery.

As natural, technological and manmade disasters continue to affect modern society, response systems and networks involved in crisis management have grown in complexity as well. Within those systems there exist actions and interactions of local, state, and federal agencies, private and nonprofit organizations, faith groups, unincorporated groups of local actors connected by tight and loose relationships [13]. Uscher-Pines et al. [14] noted 75 Federal Emergency Management Agency (FEMA)-declared major disasters in the United States in 2008 while globally natural disasters alone affected over two billion people in 2000s. In the United States, since 9/11 and Hurricane Katrina, the Homeland Security and Emergency Management complex spurred national directives, policies, and frameworks aimed at improvement of crisis management processes. Of those, planning and preparedness have taken center stage. Concurrently, communities and households - a local bedrock of emergency management system have been called upon to become more prepared for emergencies and purportedly more resilient. Ironically, initiatives for citizens' preparedness 
through campaigns such as Ready.gov, America's PrepareAthon, or National Preparedness Month among others have generally found little endorsement by Americans at large. Moreover, research has not offered compelling evidence for those programs to be generally effective even though "Emergency managers assume that encouraging citizens to prepare is constructive because preparing requires little time and effort and has no obvious downside... families whose daily lives are dominated by concerns about poverty, unemployment, and violence may consider government exhortations to prepare for an earthquake or terrorist attack as misguided at best, and out of touch at worst" [14, pp. 171-172]. FEMA's [15] 2009 Citizen Corps National Survey results revealed public outreach and education campaigns were ineffective with respect to local preparedness. The most recent FEMA report [16] represents grim preparedness profile based on 2014 records: 14\% of the publics endorsed disaster preparedness activities; $21 \%$ were working on it, $18 \%$ had it on their mind, and $46 \%$ did not even consider it. Meanwhile, the disaster response system albeit robust, follows bureaucratic patterns thus grounding response in traditional norms [17]. Its components exhibit rigid structures and vertical hierarchies of authority, yet routine preplanning activities are inadequate in non-routine situations [18], [19]. Extreme, unprecedented events like HH defy predefined directives, routines, and worst-case scenario contingencies [20], [21]. While the premise is that government can plan for disasters [22], [23], some (for example [24]) have considered such plans persuasive, illusory, and informed by political ends. In this study we endeavored to explore through our own crisis response and short-term recovery immersion experiences in $\mathrm{HH}$, how despite low community preparedness levels coupled with breakdowns in bureaucratic disaster management structures, communities persevered, people got saved, and the response was generally considered effective. In other words, we looked for illumination what processes contributed to the system not collapsing into chaos.

\section{METHODOLOGY AND ANALYSIS}

We selected autoethnography "a methodology that allows us examine how the private troubles of individuals are connected to public issues and to public responses to these troubles" [25, p. vii] as design. Autoethnographic (AE) inquiry allows for the dual role of participant and researcher [26], interpretation of connectivity between self and others [27], [28], and reflexivity [29]. Even though AE has been popularized as individual, evocative methodology, collaborative approaches have emerged favouring multi-researcher designs (duo ethnography, co-ethnography, collective AE, co-autoethnographic, co-autoethnography (CAE), community autoethnography, and community-based ethnography); researchers [26] note that in spite of nuances in labels, "CAE is emerging as a pragmatic application of the autoethnographic approach to social inquiry" [26, p. 21]. We have adopted the CAE term because our $\mathrm{HH}$ investigations adhered to the tenets of the method being (a) self-focused; (b) researcher-visible; (c) context-conscious; and (d) critically dialogic [26]. We were particularly attentive to the critically dialogic [30] aspects of our journey because it strengthened the need for ongoing negotiations between our own differing approaches to the field of disaster studies (pragmatic vs critical theory). The dialogic aspect of CAE forced us through difficult conversations, self-disclosure, and conflict often putting us at the boundaries of testing our own assumptions, with areas of convergence and divergence. Inarguably, as advocated by [26] dialogic iterative analysis of self and both led to mitigation of (a) researcher subjectivity; (b) balance in power-sharing; (c) enrichment of the research process; (d) deeper learning of self and both; and (e) community building.

As volunteers in $\mathrm{HH}$, our direct experiences were separate (both spatially and temporally). Moreover, as prosocial responding is dissipative [31], we had to rely predominantly on evocative anchoring (relying on emotional self-reflexivity [32]). Further, engagement in the 
community at sensitive and emotionally charged intervals prevented us from traditional data collection such as note-taking, image artefacts, or structured debriefings. The analysis of those experiences progressed post-facto and sequentially (contributing to the pool of data one person at a time). However, as we expanded our CAE to associated interviews, classroom practice and exchanges with students, participation in community meetings, brown bags, after action reviews, joint conferences and meetings, our experiences and CAE conversations became more aligned, concurrent, and "akin to more conventional ethnography, grounded on ethnographic data collection, analysis, and interpretation" [26, p. 19]. This is not to say however that the analytical dimension superseded the evocative one; in fact, our iterative CAE always resonated back to our specific crisis and personal epiphanies of direct experiences in the evaluation on new data intersubjectively. Epiphany can be described as "singular, unique experience" [33, p. 173] that illuminates larger understanding of underlying phenomena. Moreover, epiphanies are characterized by deep revelations during events, leave lasting impact through which "interpretative researchers attempt to secure self and personal experience stories that deal with events ...that leave effects at the deep level of a person's life" [34, p. 130]. Whereas we discussed general epiphanies experienced during HH within the concept of an ideal community elsewhere [35], the specific contribution of this study lies in the interweaving and distilling of our own response and short-recovery tension trough groups of others immersed in the context of $\mathrm{HH}$.

We used QDA Miner [36] for data management, coding, and analysis. First, we extracted a priori four figures from our field research. We agreed each was symbolic and symptomatic of (a) how planning/preparedness processes fail to address complex crises marked by unprecedented unpredictability (as in $\mathrm{HH}$ ); and (b) how the analysis of mechanistic and linear processes alone does not capture the nuance of individual and group actions in dynamic contexts. Figs 1-3 depict revelations of shortcomings in planning processes we identified during our engagement while Fig. 4 represents emergent outcome of nonlinear individual and group actions.

The assistance request process depicted in Fig. 1 has been described as "a fast and simple process flow designed to empower local municipalities with ability to request resources, information and mission assignments with less board setup time and more visibility from state level down" [37, para. 1]. It is noteworthy that areas symbolized by a hand icon denote formal approvals by qualified officials in order to push the order down the path. In clear skies (absence of an emergency or disaster) the process might take approximately 20 minutes when all authorized personnel are in one location and available to make request decisions. The use of the State of Texas Assistance Request (STAR) system during HH was not optimized. In our analysis of data, the STAR process pictogram served as an exemplar of constraining forces among emergency management professionals involved in Harvey response and shortterm recovery in Texas.

Fig. 2 represents qualitative assessment of the effectiveness of communication protocols during $\mathrm{HH}$ by the American Red Cross (ARC) disaster managers (on a scale of 1 = Poor to $10=$ Excellent $)$. Due to regionalized structure of the organization there was a clear disconnect with volunteer base at local levels. This manifested itself by inability of drivers with logistical support to access community areas unfamiliar to them topographically, timely processing and communication of resource needs, proper allocation of resources to areas most affected by the storm, tracking of resources, effective use and activation of existing local volunteer base (the ARC volunteer management platform called Volunteer Connection collapsed shortly after the rainfall), and lack of interoperability with other agencies and sheltering and feeding 


\section{RESOURCE REQUEST PROCESS}

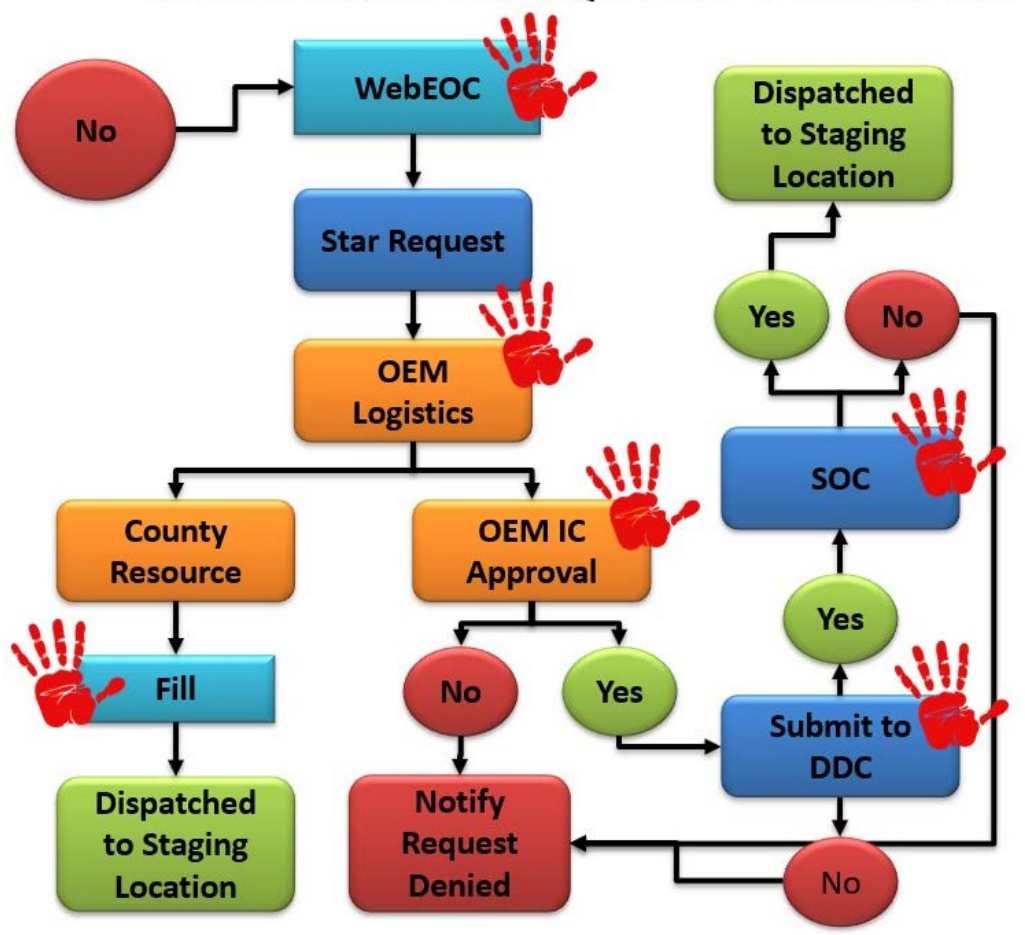

Figure 1: Standardized STAR adopted by governmental crisis management in the state of Texas. (Source: Authors.)

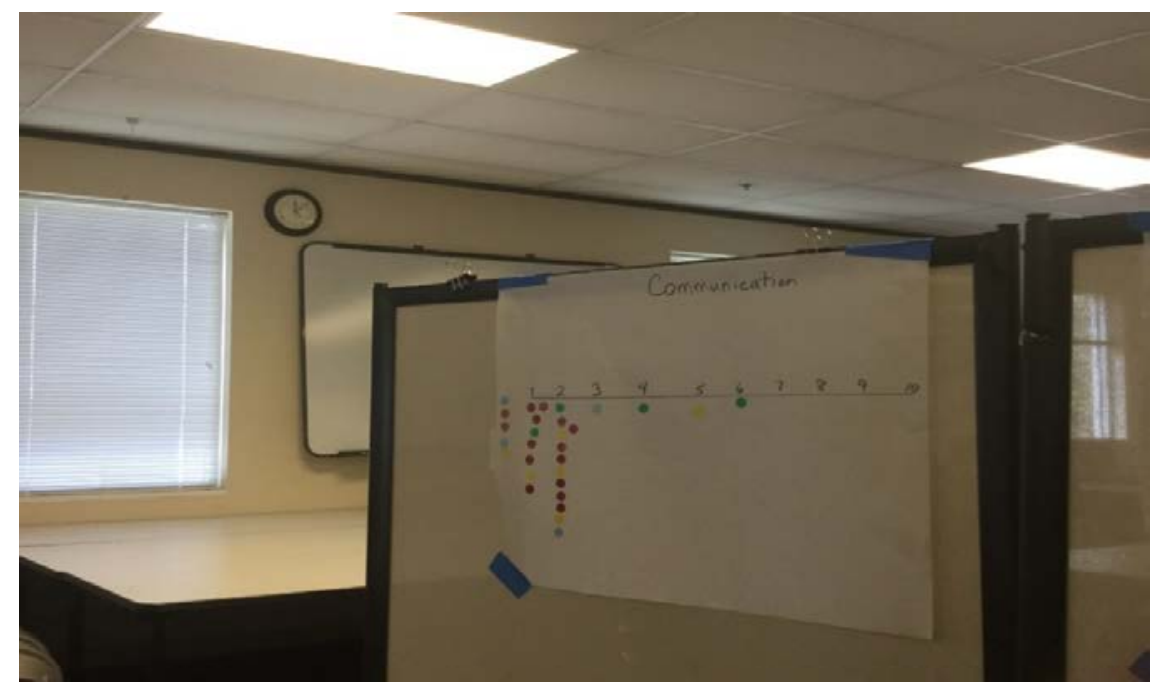

Figure 2: Assessment of the effectiveness of communication protocols by the ARC management in $\mathrm{HH}$ after action review briefing. (Source: Authors.) 
facilities. In our analysis of data, this figure grounded our field experiences and observations in both Liberty County and Harris County as well as interviews with credentialled NGO volunteers at those locations.

Fig. 3 represents efforts at the Harris County Office of Homeland Security and Emergency Management to establish volunteer database of credentialled boat operators with eligible equipment who could augment limited water rescue resources in $\mathrm{HH}$. Overall, the final record in a form of a spreadsheet listed 237 records across areas of Spring, Tomball, North West Houston, West Houston, Katy, Interstate 45 South and Southeast Houston, Houston inside 610 Loop, along 610 Loop, Northwest Houston, Sugarland and Richmond and Southwest side, Humble, Kingwood, and East Houston, Pasadena, Baytown, Montgomery County, and those identified as 1-4 hours outside of the Houston area. Overall, those records do not reflect the scope of watercraft volunteer response in HH. It is noteworthy that volunteer reception points recommended by best practice in planning did not operationalize in the hours after $\mathrm{HH}$. This figure grounded our analysis of uncredentialled spontaneous volunteers' experiences in $\mathrm{HH}$.

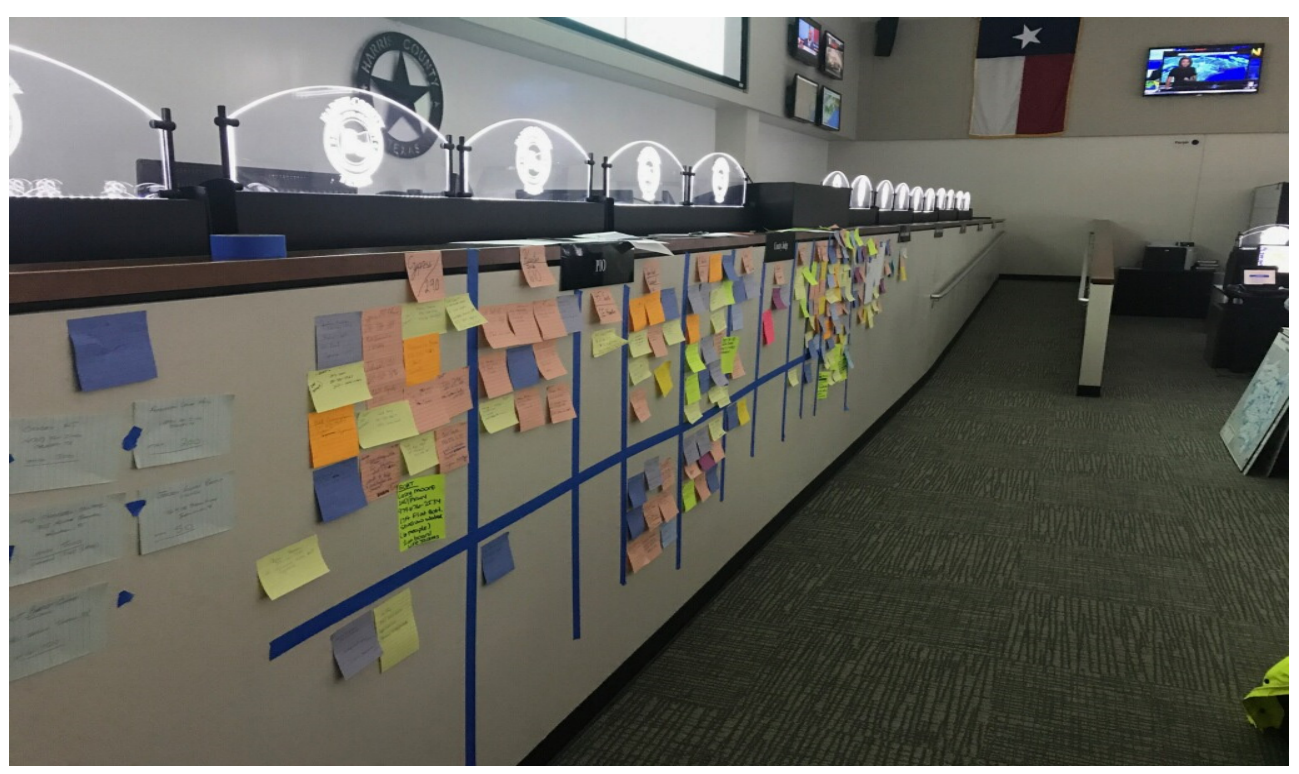

Figure 3: Volunteer tracking system at the Harris County Office of Homeland Security and Emergency Management.

Fig. 4 represents a website mapping platform created amid $\mathrm{HH}$ to alleviate challenges in communication of rescue needs. It linked spontaneous volunteers with citizens asking for help in their respective geographical areas. It evolved into a crowdsourcing tool and ultimately into a not-for-profit disaster relief organization. Fig. 4 grounded our coding related to self-organization and emergence.

Subsequently, for this study we used the corpus of 40 hours of structured interviews, shorter ad hoc interviews with 30 individuals, 100 hours of immersive field-experience by researchers, 40 hours of observations and engagement in community events and post- $\mathrm{HH}$ 


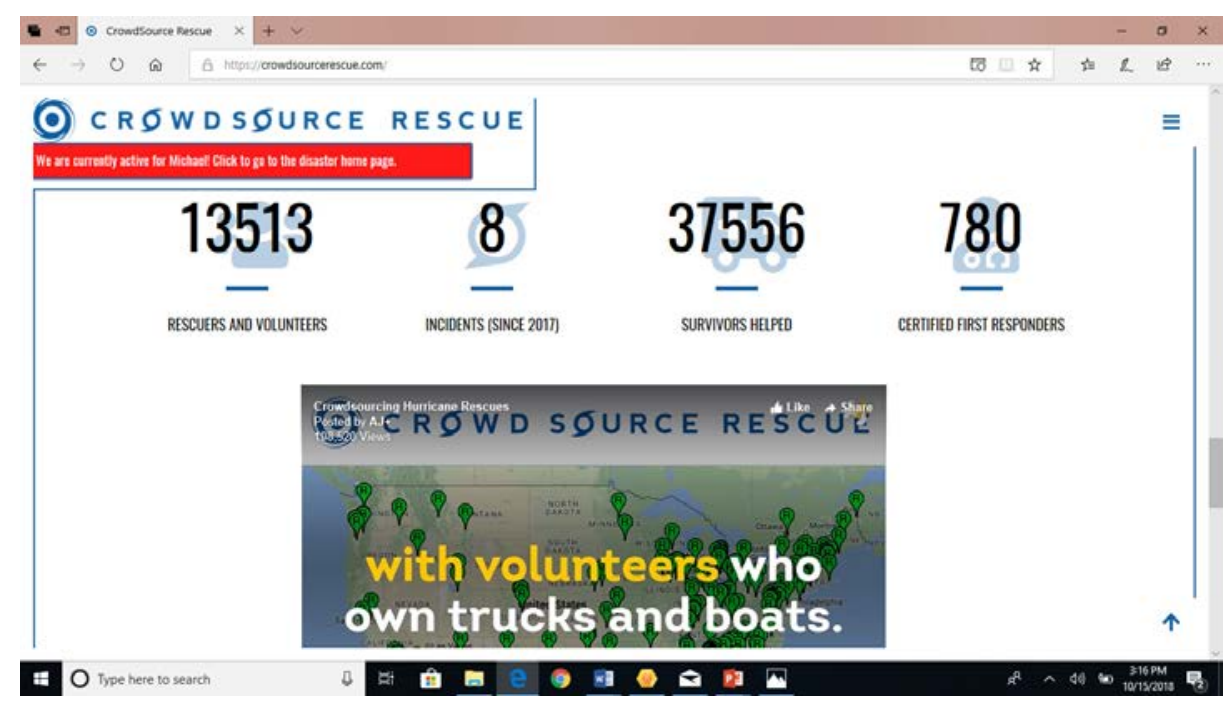

Figure 4: Crowdsource rescue application used by spontaneous volunteers in HH. (Source Crowdsource Rescue Services.)

panel sessions as well as selected analysis of Crowdsource rescue data (total 7,700 records) and archival documents. We coded, linked, and interpreted data that were directly associated with behaviors, decisions, and actions of individuals in our study (to include ourselves) who engaged in response and short-term recovery during $\mathrm{HH}$. Next, we attempted to discern an overarching tension identified across all groups of respondents, shared by both of us and offering deepest and most impactful revelation when interpreted within the rest of the data and with respect to the research question.

\section{RESULTS}

\subsection{Unstrapping}

The first author's previous experience in emergency management (e.g. staffing an emergency operation center during hurricanes and special events, volunteer work for the ARC, and teaching practice among others) instilled in her the obligation to follow procedure and process against self-dispatching, deviance from existing protocols, or acceptance of uncredentialled volunteers in disaster. In HH she consciously broke all those rules. She did not heed recommended evacuation orders for her residence, she circumvented ARC processes she found ineffective in shelter management, pet-care and donation management; she communicated outside of formal protocols and advised others - to include spontaneous volunteers - to take actions inconsistent with official messaging. The concern about her actions being deviant and misguided coupled with reflexivity on exemplars (Figs 1-4) about structured planning processes and spontaneous action guided our data analysis process. In negotiating our data against our own lived experiences during $\mathrm{HH}$, the Unstrapping became focal because it was revealed across all groups represented in our research which was the purpose of our current study. Specifically, professional emergency responders, elected public officials, citizens affected by the flood, faith group leaders, as well as formal and informal volunteers knowingly and independently engaged in the practice we termed Unstrapping. We 
came to define Unstrapping as individual or group action undertaken in contradiction to existing standard operating procedures (SOPs), standardized formal processes, organizational communication protocols, or public warnings occurring as a normal human response to conditions constraining sense-making in large scale events. Our data allowed us to discern Unstrapping occurred along three major categories: (a) backchannel communications; (b) circumvention; and (c) violation. Each of those categories was characteristic to different respondent groups in our study albeit some overlapped.

Backchannel communications occurred predominantly among professionals in emergency management, elected officials, and management staff of NGOs (paid positions). It was displayed among personnel at mid to mid-upper level of management who had domain knowledge, subject matter expertise and established networking relationships allowing them to access alternative openings and connections to overcome process or system inertia or failure. Backchannel communications were consistently discovered in after action reports (AARs), personal interviews and unstructured field-work debriefings. Many responders who engaged in backchannel communications in our study stressed high levels of risk associated with their decisions to unstrap. Specifically, decisions to use backchannel communications were accompanied by fear of termination of employment, reassignment, demotion, loss of political appointment, organizational ostracism, and loss of esprit de corps within the agency/organization or professional community. Perceived risks associated with backchannel communication unstrapping cannot be underestimated as we found evidence unstrapping in Harvey was perceived as threatening to emergency management and response institutions. Specifically, official AARs we analysed stressed backchannel communications were needed to be eliminated "the availability of resources during $\mathrm{HH}$ was a significant issue for the initial 72 hours of Harris County's impact. Automatic and mutual aid response assets were unavailable due to the widespread geographic impact of the region. Along with local resource availability issues, the State was receiving requests for resources all along the Texas Gulf Coast. Each jurisdiction was experiencing their own internal disaster and those who were minimally affected were unable to provide resources due to mobility issues. These issues created an environment where the prescribed processes for resource requests were being circumnavigated by local responders via back channels to various State and Federal officials. The process for resource allocation through 'back channel' communications greatly reduced the ability of personnel, at the local level, who were involved in determining the operational priority of resources. However, back channel communications outperformed formal prescribed methods for resource requests. Recommendation: Local response agencies should follow local basic plans and the State's plan for resource requests. State and Federal Officials should enforce plans for resource ordering". In addition, few responders in our study who engaged in backchannel communications reported early retirement, reassignment, or loss of position within an agency post Harvey. In juxtaposition, we interpreted the Unstrapping by Backchannel Communications as a successfully adaptive behaviour underlying the phenomenon of sense-making in high consequence-high risk events.

Circumvention consisted of modifying, altering, or sabotaging established routines, processes, or guidelines and manifested itself among formal volunteers as well as spontaneous responders who sought ways to solve challenges. Unlike backchannel communications, those respondents who engaged in unstrapping by circumventing relied on common, everyday knowledge and optimal solutions available to them without a vast network of connections or specialized domain expertise. Concurrently, because of their lower degree of emergency response or political affiliation (e.g. credentialed volunteers) they reported lower levels of anxiety when assessing risk and consequences of their actions. As one of the ARC volunteers confided "yes, I know I am not supposed to be taking the shelter 
resident into my car to get their medications; what are you going to do? Fire me from volunteering?" Examples of circumventing included abandoning posts in which they were assigned in place and not utilized, re-emerging at different locations when told to go home and stay there until needed, switching officially assigned duties to attend to staffing gaps identified ad hoc, rearranging resource pathways, altering ways and routes of distribution, modifying established processes, or engaging in activities beyond the scope of the suggested protocols. Unstrapping by circumvention was the most pervasive which we attribute it to lower levels of perceived distributed risks and vast numbers of credentialled volunteers and spontaneous responder-citizens we met in our study.

Violation or direct rule-breaking occurred mostly among spontaneous, unaffiliated citizen responders and flood victims. It manifested itself in disregard to SOPs, organizational arrangements, formal communication flows, emergency management processes, and resource use protocols. Those engaged in unstrapping by violation rejected warnings, defied existing authorities (intentionally breaking road blockade to access event site, wading in toxic waters in spite of risk communications to avoid those areas), or sought untested solutions (e.g. attempting kayak rescues in swift waters) in the absence of formal response. As echoed by one of the citizens those unstrapping by violation represented the extreme urgency of action in the absence of imminent actionable plans "they don't know enough in the aspect of is this safe, is this right, do I have to have a permit, do I have to apply for this particular funding grant...they don't wanna wait for someone else, they don't wanna wait for government to help them, so they out of the sudden build this sense of resiliency as well. That is the majority of the population. Resilience is not something you build - it's when crisis happens people just do things". Indubitably, the unstrapping by violation category was most threatening to official emergency management structures. Our data suggested most of emergency management professionals (albeit not all of them overtly) decried unstrapping by violation as irresponsible, high-risk behaviours detrimental to official response and shortterm recovery efforts (e.g. liabilities). In fact, many used the term "evacuations by convenience" explaining that many residents who did not need to evacuate did so because of opportunity rather than need. Our analysis of Crowdsource Rescue data of residents requesting rescues did not confirm that. Conversely, spontaneous action during $\mathrm{HH}$ has been concurrently depicted as transformative "considering the disaster magnitude the death toll in Harris County was mercifully low, in large part due to the bravery and generosity of Houstonians: people who launched their fishing boats to rescue strangers trapped in their homes, or on their roofs...the surgeon who canoed to is hospital to perform emergency surgery on a teenager, a midwife who paddled an inflatable swan to help a patient in labour" [2, p. 87]. Considering inherent issues of planning and preparedness that do not translate well on the ground in response and short-term recovery in unprecedented catastrophic events (Figs 1-3), judgements such as un-preparedness and the idea publics are threatening in disaster situations allow institutions to pass responsibility of poor response to vulnerable communities. They might also foster the illusion that strong planning as well as command and control approaches to disaster response are fundamental when it could be that underlying phenomena such as unstrapping are equally important. For each of the types of Unstrapping we discovered, we created representative storyline narratives whose elements we found useful to then link the Unstrapping to theoretical lens, namely the complex adaptive system's (CAS) framework. The vignettes portray selected examples of real $\mathrm{HH}$ contexts that led to unstrapping and underscore that actions taken by those involved in response and short-term recovery were short of chaotic, but deeply purposeful. Most importantly, those narrative write into our lives [38], [39] because we crystalized our own experiences through becoming more aware of our identity development as disaster researchers. 


\subsection{Unstrapping vignettes}

\subsubsection{Rheba: The backchannel communicator (professional emergency responder)}

Rheba had more than 20 years of experience in Fire Response and Homeland Security at the time of HH. She had attended many FEMA programs and was an ardent advocate for simulated forecasting of flood impacts in the city of Houston. In 2016 with new governance for the city (new mayor, new fire chief, new police chief), she lost political clout in a new system. On the eve of Harvey, watching National Weather Service forecasts she knew the hurricane would be devastating. "We were going to be trapped in small islands in the city" she thought and shared her predictions with superiors. Meanwhile, management was thinking business as usual "Even on the eve of the rains on Saturday morning they were still managing everything as business as usual" she recalled. Even though the fire department had a plan for activation, the new administration had not read it "it is a very large document and often boring". It did not help that the new fire chief during non-existent transition (in the middle of the hurricane season in July 2017) kept only three of the ten of his executives. In August when Harvey struck, they were still trying to figure out the layout and parking spots in the new building. In absence of pre-activation Rheba watched first as the city flooded, then as people moved around in boats, jeeps with snorkels, and semi-organized groups she referred to as swamp people. Meanwhile, her and her crew had absolutely nothing to do but watch it rain. By Sunday, the decision was made to open the dams to prevent potential catastrophic failures; thus, entire neighbourhoods were purposefully flooded. A year earlier catastrophic failure of Addick's and Barker reservoirs was considered. Rheba herself delivered a briefing with simulations suggesting in 90 minutes after dams' failure 100,000 people would be lost in Houston's chemical junk mudslide travelling into the Bayou. She suggested officials consider those zones for pre-evacuations. No evacuation orders were ever considered during Harvey in Houston. By Sunday Rheba assessed data and predicted continued deterioration, extreme flooding, and a total shutdown of the region for at least a week. She was further worried that even if the dams were open, they were still vulnerable to breaking. Concurrently, the mayor did not want to call in state or federal resources out of fear for losing jurisdiction over the city. Despite being told by many public safety officials that is was time to call for aid, he remained unwilling to do it.

Due to her years of professional experience, Rheba possessed deep connections at the state level. She knew a lot of people and navigated back channels very well, so she decided to make inquiries about reaching state help without formal request for help. On Sunday morning she reached out to risk management for the state of Texas, presenting intelligence and assessment contrary to her chain of command and beyond the scope of authority. Upon her alarming reports state representatives started exerting pressure on Houston Emergency Center and within an hour Rheba got confirmation from the state that the aid will be coming. Indeed, because state resources were pre-staged, help to Houstonians started flowing within 3-4 hours "floodgates of help opened up" Rheba reminisces with a smile. By Monday the management got tired of Rheba sending updates and she was asked to report to George R. Brown Convention Center to Unified Command - they were multiple commands; in fact, Rheba suggested none of the command structures mirrored textbook prescriptions of Unified Command or Area Command. It was very messy. Rheba continued her work straight to attend to medical emergencies such as Ben Taub and St Joseph's hospitals. She took early retirement from her agency a year after the hurricane. 


\subsubsection{Margaret: The circumventer (credentialled volunteer)}

Margaret had been an ARC volunteer for 5 years by the time HH hit. She had previous law enforcement and educational background and on the eve of Harvey's landfall she tried to obtain her assignment to assist with shelter operations in Montgomery County; unfortunately, she was unable to register because the Volunteer Connection platform for assignments and scheduling collapsed. It was not until later in September when she was finally able to reconnect and reengage (by then the organization was much beleaguered by criticism of ineptitude in $\mathrm{HH}$ direct aftermath particularly with deployment of sheltering plans). By the second week of September the ARC was organizing to help phase out various sheltering operations particularly those housed in smaller faith centers, or civic centers that needed to resume their regular services to communities. Part of that initiative was the activation and dissemination of the Immediate Assistance Program (IAP) - a \$400 cash stipend for individuals from 39 Harvey affected counties based on the following criteria: (a) primary residence was severely impacted by the hurricane; (b) household became displaced because of the hurricane; (c) household needed emergency assistance; and (d) residence could be verified in one of the 39 counties. Margaret was asked to oversee the launching of the IAP in several shelters in Liberty County. She received a brief just-in-time training for the IAP and participated in three initial days of its roll-out. The components of the operationalization of the IAP consisted of a Tablet used by ARC volunteer to gather pertinent data and application details. ARC volunteers were to assist applicants to (a) create an online ARC account; and (b) receive a code via email or text message that would then be used in Walmart or MoneyGram International to collect cash. ARC volunteers were advised that they could only guide applicants through answers to the questions and were instructed to not record or retain any identifying information; in case of language needs they were to switch applications on the Tablet to another language for the applicant.

Several things became immediately apparent to Margaret, who was not a resident of Liberty County herself, nor had she ever before visited the area. First, neither Walmart or MoneyGram locations were accessible to persons without transportation or with mobility issues in shelters she worked. Second, many elderly in the shelters did not have smart phones to retrieve their emails (most of the did not own email accounts); many still used landlines in homes they vacated and many of those who owned flip-phones did not have chargers and had not had access to phone communications for days (shelters generally could not provide chargers for old models of phones). Thirdly, many Latino shelter visitors and residents did not have email accounts or felt extremely apprehensive about using them in the application process; it was evident many of the applicants did not have a documented status. Finally, the language switch interface used google translation which prevented recorded data to be integrated properly because in Spanish language dates are spelled in reverse of English standards. Thus, the system would automatically deny those who used Spanish interface because of its inability to execute verification. "I had a choice of going through the motions, knowing that many applications will be denied, rejected, or simply impossible to operationalize. I realized IAP inadvertently discriminated and marginalized just by its design. But I also believed in the Red Cross, after all it tracked my relatives after WWII. I decided to get creative and go on a limb".

For three consecutive days Margaret circumvented formal IAP roll-out processes in order to secure as many approvals as possible. After all, everyone housed in those shelters (often called shelters of last resort) was eligible. If it was to her, she would be distributing cash to every individual asking for it. First, in spite of strong policies against driving disaster victims in personal vehicles, she personally escorted several elderly individuals and mothers with children to Walmart and MoneyGram locations to pick up their cash - "You know I was a 
cop - I can do my risk assessment fairly well" she noted. She established on her own electronic devices numerous email accounts where applicants could receive emails with their passcodes; at times she was concurrently establishing email accounts on her cell phone, iPad, and laptop she brought in on a third day. She encouraged Latino applicants not to use their native tongue and trust her with data input in the English version of the IAP; she gathered dozens of notes with personal identifying information so that she could ascertain which accounts and codes belonged to whom. In short, she ran a circumvention enterprise within the ARC with numbers of rejections declining by day 3. "We tried to fix and alter everything that seemed to be wrong with the system but thinking back the system was total crap and people deserved better". Margaret continued to work in shelters and remained involved with the ARC at the time of our study.

\subsubsection{Matt: The circumventer (spontaneous citizen responder)}

For Matt thinking about Harvey started "unceremoniously" - planning was not on his mind. He remembered people overreacting after hurricane Katrina and evacuating Houston needlessly for Rita. On Saturday night his thoughts were on a televised fight. He woke up to flooding in Houston area of Memorial City/Memorial Villages, so he jumped on his bicycle to take stock. Realizing that some areas received more than 10 feet of water, he estimated his Emergency Medical Technician credentialing (albeit by then expired) could make him useful in disaster. However, when he approached formal responders offering help, they sent him to report to staging area at a fire station 3 miles away. Had Matt driven a car, he might have reported there, and he would have been turned away as many others were, he reminisced. However, Matt assessed biking 3 miles in high waters was a waste of precious time. Instead, he folded himself into uncoordinated, private boat operator rescues and made seven trips in 6 hours on Sunday afternoon; all residents reached by boats (as well as their cats and dogs) wanted to be rescued.

Matt absorbed details of spontaneous actions taken, listened, took pictures, memorized streets and topographical markers. Later that night when official responders could not come up with a plan to rescue isolated residents of the community hit by lingering water bands, Matt's local church was in desperate need of solutions beyond official help. Matt and his business partner decided to use some of the information gathered by Matt and launch a website - matching people who want rescues with those who wanted to help. They put it up in a matter of hours, though Matt remembered thinking late Sunday night newspaper headlines might read "idiot develops a rescue site" on Monday. On Monday, however, there were hundreds of people weaving through the site and incident numbers started to grow exponentially as the site became what is known today as Crowdsource Rescue Services (CRS). By the end of 28th August, the application Zello - a free walkie-talkie app - became spontaneously adapted to dispatch service matching those being rescued with the rescuers; Cajun Navy (volunteer group of boat operators from Louisiana) among others merged into the rescue effort as well. Matt focused on short phone calls conceptualizing the platform for its users, troubleshooting, and advising people not to use 9/11 system which by then was generally overwhelmed and ineffective. He realized circumventing 9/11 communications was the best course of immediate action even though he admits he realized some redundancy of effort would become an issue later; wading in a new territory, he was concerned that is platform might spiral into "Wild West" as spontaneous response tends to be depicted by emergency management officials. He spent 20 hour days providing training to dispatchers and managing the companion Facebook site.

Over time immediate rescue connectivity of the CRS became augmented by folding into it a hotline sex trafficking center. Specifically, the center with professional crisis counselors 
shifted their operations to Harvey using 150 call takers and adapting existing scripts and templates to provide rescue wellbeing follow-up services. The number of volunteers in Matt's and his partner's office swell as well. Self-organizing complementarity of emerging services was hardly managed at all. Matt recalls one of the proudest moments - a local news anchor reached to Houston police to help rescue her friend trapped in a car and lodged in swift waters. However, Houston police did not have boats available, so CRS disseminated its number to match anyone who would geographically fit the area; the communication conducted over Zello was captured by the coastguard who leveraged the crowdsourcing and sent a unit to the location. Overall, during its 3 day rescue operation in Houston alone (it was ultimately leveraged for Beaumont, Port Arthur, Louisiana and even Puerto Rico response to Maria) CRS Houston housed a repository of 7,700 records of households that were evacuated during Harvey. Low estimates indicate 25,000 individuals were reached. Today CRS is a nonprofit disaster rescue organization while Matt remains actively engaged in Texas disaster legislature as well as networking with researchers as well as professional and spontaneous disaster communities.

\subsubsection{Andrew: The violator (spontaneous citizen responder)}

Andrew was a Texas University student at the time of HH. On 26th August, a friend from Minnesota arrived with a boat to lend hand in imminent rescues. Andrew contacted the local emergency operation center (it took him 30 attempts to get through on volunteer hotline) and was told help was not needed. However, technologically savvy young man could not be deterred. On 27th August Andrew and friend loaded the boat and decided to follow the I-45 Interstate South until the road would be impassable despite warnings to stay off the roadways because of the risk of closures; he used Zello that connected him to rescue communications traffic. In his assessment, where the road would end, people would be flooded and needing help. Indeed, in Cypress Wood they ran into the Spring Branch fire department who desperately needed help and did not have a boat so they followed them around in a low income community moving people out of trailer homes "So we both had our water gear on and then we went out there and physically grab like help people you know get into boats, assist in any way we could get them to a little higher ground"; their depth finder was reading 37 feet of water in some areas. On the 28th Andrew communicated via Zello with Cajun Navy who instructed them to go to Port Arthur (LA) because they needed people with boats there. On a way to Port Arthur they were driving with her life jackets on is a very large fourwheel drive, lifted-up SUV. Even though they operated in risky environment, they followed an 18-wheeler that pushed water away. Finally, when they got to the last stretch of freeway into Port Arthur, the two-lane road was packed with a mile-long stretch of vehicles and boats. When they were finally out of the flooded stretch there was a sheriff standing in the middle ordering all to turn around denying access.

It took 5 hours for the mile of cars with boats to get turned around back towards flooded highway, but Andrew and hundreds of others found a blocked offramp on the other side of the road where the sheriff wasn't and made it through anyway. Past that point they passed various units of coastguard, Cajun Navy, dozens of volunteer organizations, and citizens active in response. Andrew commented that the only time he came across first responders it was the fire department in Spring on the 27th and the sheriff in the middle of the road. There was no centralized command at any point in Port Arthur, yet things were moving. After numerous rescues and navigation help from local resident, they came across a nursing home where the manager did not allow anyone to be removed; the policy was to wait for coastguard helicopters. Andrew and friend looked at the people in wheelchairs water reaching their stomachs, oxygen tanks getting to empty and started triaging of bedridden and wheelchair 
bound who needed to get out first. The told the manager they were sending pictures of the facility to the Media. They generally took control over and dispatched for help from one official coastguard member; soon after, they initiated moving people out of the nursing facility onto the boats (by then they had a chain of them and hundreds of volunteers to help) and to the bowling alley area which served as medical point and from where they eventually would be airlifted to another city (Conroe). The area swarmed with nurses and medics. Each trip from the nursing home lasted 20-25 minutes and Andrew recalled grabbing medical records "You know we have huge bags of medicines. The entire medical history and records for the entire nursing home everything in a trash bag multiple trash bags that were in the boat". He had to for the first time in his life change an oxygen tank - the patient was put on their boat with 5 minutes supply for a 20 minute ride. Andrew remained in Port Arthur performing rescues and merging with Cajun Navy volunteers while his friend flew with rescued patients to Conroe. Andrew graduated and currently works for local emergency management.

\subsubsection{Jenny: The violator (engaged citizen in a community affected by floods)}

Jenny was instructed to evacuate her home in an established retiree golfing community when water was suddenly released from lake Conroe. The local fire department knocked on doors urging people to leave. She briefly considered a hotel, but ones in the proximity were full. She was not willing to drive 200 miles to Dallas. She knew there were others in the area who would stay - they had nowhere to go, no finances to pay for hotels, or no mobility. Among those were the bedridden, the elderly, the widowed, the undocumented - she directly knew many and knew of the most. Moreover, she had political connections with an elective county official and sensed she might be needed to get some strings pulled. Even though she never really looked at the flood zones' map that hang on the community wall office where she volunteered for years, it did not matter much she recalled - she knew they were flooding and that it would be bad.

Thus, Jenny violated the evacuation order and immediately went into action; she helped people move selves and belongings to higher floors in their homes, she kept notifying those who evacuated about the status of water levels, she provided information to citizen boat operators who came to rescue those stranded (some of the homes in her community were flooded up to 12 feet high). She coordinated with the official she knew to secure waste zones and debris removal services immediately after the storm. All the while, she was able to weather the storm in her home. Immediately after waters started receding, Jenny realized the speed of short-term recovery was critical. She set up a community center which in the following 14 days swarmed with hundreds of volunteers who came to mock flooded homes from areas as far as Nebraska. The center took form and was the hotbed on local grassroot activity before any official external aid, before her county emergency management services, before ARC (whose substandard food consisting of cold hot dogs and canned green peas Jenny refused to accept; grassroots efforts in her community provided nutritious, healthy, wholesome and efficient food service and ingenious golf cart delivery by youth for all victims and spontaneous volunteers), or before FEMA. After the storm Jenny became an ardent advocate against the planned sale and subsequent urban development of the golf course (the only natural watershed in the community). She is leading citizens' efforts of the community to purchase the land and turn the area into the green belt in order to mitigate future catastrophic floods. 


\section{DISCUSSION AND IMPLICATIONS}

Unprecedented catastrophic events like HH create a state of disequilibrium. In such a state, systems involved such as response organizations, volunteers, NGOs, and victims are moved away from their routines. A CAS displays adaptive tension which triggers emergent selforganization, spontaneous yet purposive rearrangement of components without central control [40]. Evidently, complexity seems to be an important concept for understanding modern government and governance processes. Nevertheless, the domain of emergency management (and in the US associated homeland security studies) have not yet made extensive use of the concepts and ideas of complexity theorists. CAS concepts have had limited influence on theories of emergency management with some exceptions noted in resiliency and disaster risk reduction, e.g. [41]. Recently, [42] defined the following five characteristics of CAS: (a) network of many differentiated agents; (b) emergent quality; (c) no central control; (d) multiplicity of interconnections, integrations, associative behaviour; and (e) evidence of system learning [42, pp. 1093-1094]. We propose that the Unstrapping we discerned through our study is one representation of adaptive tensions experienced throughout the response and short-term recovery system during the hurricane. Such tensions triggered repairs (through back channel communications, circumventing, and violation) and emergent self-organization serving as catalyst to counterbalance processes working during periods of stability and characteristic of mechanistic systems.

Specifically, unstrapping might help account for how systems during response and shortterm recovery did not fail given purported $84 \%$ of population in the US does not prepare for disasters and indications of government inadequacy or NGO planning revealed through our research. There are several implications of our findings. First, in order for a system to be considered a CAS, there has to be evidence of system learning [42]. Therefore, emergency management governance requires an understanding that nuanced unintended/unanticipated patterns of behaviours that emerge in catastrophic events are a norm rather than deviation. Echoing [43] "the complexity and the multiple, emergent properties of complex systems will make these systems unmanageable... The argument is that since dynamics, self-organization and emergence are the norm, adjusting to these changes is often a wiser strategy than trying to get a grip on them. In this situation, a manager adjusts and adapts to developments rather than directing them" [43, p. 313]. In other words, emergency management governance will continue to run on what researchers [44], [45] labelled the edge of chaos. Admittedly, in Harvey the biggest factor of system learning was ultimate realization that efforts to direct or "manage" or direct spontaneous force were futile. Ultimately, "ad hoc civilian responders turned out to be a huge asset.... Instead of turning them away, Texas and Florida welcomed them and helped coordinate their efforts. It was a necessary element in the field" [46]. For the ARC, the experience with Mega Shelters altered their philosophy on sheltering with stronger focus on including community centres, or faith and Samaritan groups that repaired ARC breaks in sheltering plans during Harvey.

Second, social research tends to consider social dynamics through the lens of society or community as a heterogeneous set of individuals and ensuing policies and plans (e.g. evacuation planning, sheltering, IAP roll-out) generally reflect that view. Under CAS lens social dynamics play out through non-linear interactions [44], [47] of diverse sets of individuals (e.g. crowdsourcing) and studying those could contribute significantly to our understanding of how micro-level decision-making influence larger social dynamics. For example, Unstrapping and launching of Crowdsource Rescue in Harvey did not only change the context of response in time of the hurricane, but also caused changes at regional and state level (i.e. Texas 86th legislation 2019 unanimously passed House Bill 3365. It provides immunity from civil liability for a person who gives care, aid, and advice with respect to the 
management of an incident during a natural disaster). This in turn would affect various communities in the future and would support evidence of system's learning. Finally, the anatomy of Unstrapping allowed us the view Harvey response and short-term recovery through a range of tight and loose coupling patterns exhibited. According to CAS researchers [44], [45] resilient CAS displays the range of coupling patterns from loose to tight. Complex interactions of loose and tight systems in turn serve as creative pathways of adaptation under a range of conditions. In HH tightly coupled systems (e.g. governmental organizations, emergency response agencies, and NGOs) shared situational space with diverse communities and households affected as well as with dispersed spontaneous citizen responders operating in loose-coupled systems. The anatomy of Unstrapping revealed to us interdependence and complementarity. For example, spontaneous volunteers performing rescues were not constrained by thinking about liability even though formal responders were. In the words of an emergency management official: "they were in a way more resilient than us". Indeed, we met several respondents at field level who wished they could "do something" but instead were assigned "to watch it rain". One important implication for emergency management is the understanding of a shared situational space in a CAS. Only then, non-linear, emergent actions could be understood as a behavioural norm versus hindrance in critical events.

\section{REFERENCES}

[1] Blake, E.S. \& Zelinsky, D.A., National hurricane center tropical cyclone report: Hurricane Harvey. Report AL092017, 2018.

www.nhc.noaa.gov/data/tcr/AL092017_Harvey.pdf. Accessed 15 Jul. 2019.

[2] Swartz, M., Troubled waters: A year after Harvey, has Houston learned anything? Texas Monthly, pp. 84-93, 22 Aug. 2018.

[3] Harris County Flood Control District, Immediate report: Final, Hurricane Harvey: Storm and flood information, 2018. www.hcfcd.org/media/2678/immediate-floodreport-final-hurricane-harvey-2017.pdf. Accessed 5 Jun. 2018.

[4] Schafler, K., Montgomery County homes vulnerable to flooding issues, community impact. Community Impact Newspaper, Conroe Montgomery Edition, 19 Apr. 2018.

[5] Snyder, M., Final report: Harvey's impact on Houston area laid out in grim detail. Houston Chronicle, 5 Jun. 2018. www.chron.com/news/houston-texas/houston/article/ Harvey-s-impact-on-Houston-area-in-grim-detail-12969537.php. Accessed 4 Jun. 2019.

[6] Harden, J.D., Harvey recovery continues in parts of flooded Liberty County. Seattle Times, Nation \& World, 2017. www.seattletimes.com/nation-world/harvey-recoverycontinues-in-parts-of-flooded-liberty-county/. Accessed 5 Jul. 2019.

[7] Brody, S.D., Blessing, R., Sebastian, A. \& Bedient, P., Examining the impact of land use/land cover characteristics on flood losses. Journal of Environmental Planning Management, 57, pp. 1252-1265, 2011.

[8] Brody, S.D., Zahran, S., Highfield, W.E., Grover, H. \& Vedlitz, A., Identifying the impact of the built environment on flood damage in Texas. Disasters, 32, pp. 1-8, 2008.

[9] Olsen, L., Flood threat known early: Corps predicted the reservoir spill before Harvey hit. Houston Chronicle, 2018. www.houstonchronicle.com/news/houston-texas/ houston/article/barker-addicks-dams-flooding-predicted-army-corps-12632041.php. Accessed 5 Jul. 2019.

[10] Conroe Community Development Department, 2017. 
[11] Schafler, K., Homes, businesses rebuild after Hurricane Harvey: Montgomery County residents help neighbors together to restore communities. Community Impact Newspaper, Conroe Montgomery Edition, 23 Oct. 2017.

[12] Van Oldenborgh, G.J. et al., Corrigendum: Attribution of extreme rainfall from Hurricane Harvey, August 2017. Environmental Research Letters, 13, pp. 1-11, 2018. DOI: $10.1088 / 1748-9326 /$ aaa343.

[13] Nowell, B. \& Steelman, T., The role of responder networks in promoting community resilience. Disaster Resiliency: Interdisciplinary Perspectives, eds N. Kapucu, C.V. Hawkins \& F.I. Rivera, Routledge, pp. 232-257, 2013.

[14] Uscher-Pines, L., Chandra, A., Acosta, J. \& Kellermann, A., Citizen preparedness for disasters: Are current assumptions valid? Disaster Medical Public Health Preparedness, 6(2), pp. 170-173, 2012.

www.cambridge.org/core/services/aop-cambridge-core/content/view/ C3BB34848AAA4CE0A24A5B4352A28DC9/S1935789300004717a.pdf/citizen_pre paredness_for_disasters_are_current_assumptions_valid.pdf. Accessed 5 Jul. 2019.

[15] Federal Emergency Management Agency (FEMA), Personal preparedness in America: Findings from the 2009 Citizen Corps National Survey, Report, 2012. www.fema.gov/media-library/assets/documents/29972. Accessed 5 Jul. 2019.

[16] Federal Emergency Management Agency (FEMA), Building cultures of preparedness: A report for the emergency management higher education community, Washington, 2019. https://training.fema.gov/hiedu/docs/latest/2019_cultures_of_preparedness_ report_10.22.18\%20final.pdf. Accessed on 10 Jul. 2019.

[17] Schneider, S.K., Governmental response to disasters: The conflict between bureaucratic procedures and emergent norms. Public Administration Review, 52, pp. 135-145, 1992.

[18] Kendra, J.M. \& Wachtendorf, T., Creativity in emergency response after the World Trade Center attack. Beyond September 11th: An Account of Post-Disaster Research, Special Publication No. 39, Natural Hazards Research and Applications Information Center, University of Colorado: Boulder, CO, pp. 121-146, 2003.

[19] Morgan, G., Images of Organization, SAGE: Beverly Hills, CA, 1986.

[20] McConnell, A. \& Drennan, L., Mission impossible? Planning and preparing for crisis. Journal of Contingencies and Crisis Management, 14(2), pp. 59-70, 2006.

[21] Kapucu, N., Interagency communication networks during emergencies: Boundary spanners in multiagency coordination. American Review of Public Administration, 36(2), pp. 207-225, 2006.

[22] McLoughlin, D., A framework for integrated emergency management. Public Administration Review, 45, pp. 165-172, 1985. DOI: 10.2307/3135011.

[23] Petak, W.J., Emergency management: A challenge for public administration. Public Administration Review, 45(2), pp. 3-7, 1985. DOI: 10.2307/3134992.

[24] Bissell, W.C., From Iraq to Katrina and back: Bureaucratic planning as strategic failure, fiction, and fantasy. Sociology Compass, 2, pp. 1431-1461, 2008.

DOI: $10.1111 / \mathrm{j} .1751-9020.2008 .00139 . x$.

[25] Denzin, N.K., Interpretive Autoethnography, 2nd ed., SAGE: Los Angeles, 2014.

[26] Chang, H., Ngunjiri, F.W. \& Hernandez, K.A., Collaborative Autoethnography (Developing Qualitative Inquiry), Routledge: New York, 2016.

[27] Bochner, A.P. \& Ellis, C. (eds), Ethnographically Speaking: Autoethnography, Literature, and Aesthetics, Alta Mira: Walnut Creek, 2002.

[28] Ellis, C., The Ethnographic I: A Methodological Novel About Autoethnography, Alta Mira: Walnut Creek, 2004. 
[29] Adams, T., Ellis, C. \& Holman Jones, S., Autoethnography: Understanding Qualitative Research, Oxford University Press: New York, 2015.

[30] Bakhtin, M.M., Toward a Philosophy of the Act, trans. V. Liapunov, eds V. Liapunov \& M. Holquist, University of Texas Press: Austin, 1993.

[31] Perry, R.W. \& Lindell, M.K., Understanding citizens repose to disasters with implications for terrorism. Journal of Contingencies and Crisis Management, 11, pp. 46-90, 2003.

[32] Ellis, C., Evocative autoethnography: Writing emotionally about our lives. Representation and the Text: Re-Framing the Narrative Voice, eds W. Tierney \& Y.S. Lincoln, State University of New York Press: Albany, pp. 116-139, 1997.

[33] Craig, G., Everyday epiphanies: Environmental networks in eco-makeover lifestyle television. Environmental Communication, 4, pp. 172-189, 2010. DOI: $10.1080 / 17524031003775620$.

[34] Denzin, N.K., Interpretative autoethnography. Handbook of Autoethnography, eds S.H. Jones, T.E. Adams \& C. Ellis, Routledge: New York, pp. 123-142, 2010.

[35] Baker, N. \& Denham, M.A., For a short time we were the best version of ourselves: Hurricane Harvey and the ideal of community. International Journal of Emergency Services, 2019. DOI: 10.1108/IJES-12-2018-0066.

[36] Provalis Research, QDA Miner, computer software, Version 5.0.5, Montreal, 2017.

[37] Texas Interagency Coordination Center (TICC), State of Texas Assistance Request, 2019. https://ticc.tamu.edu/Response/STAR.htm. Accessed 5 Jul. 2019.

[38] Coia, L. \& Taylor M., Moving closer: Approaching educational research through a co/autoethnographic lens. Proceedings of the Sixth International Conference on SelfStudy of Teacher Education Practices. Collaboration and Community: Pushing Boundaries Through Self-Study, East Sussex, pp. 59-62, 2006.

[39] Convery, I. \& O'Brien, V., Traveller narratives: Making sense of place - A coethnography. Narrative Inquiry, 22(2), pp. 332-347, 2012. DOI: 10.1075/ni.22.2.07cpn.

[40] Capra, F., The Web of Life: A New Scientific Understanding of Living Systems, Anchor Books Doubleday: New York, 1996.

[41] Coetzee, C., Van Niekerk, D. \& Raju, E., Disaster resilience and complex adaptive systems theory: Finding common grounds for risk reduction. Disaster Prevention and Management, 25, pp. 196-211, 2016. DOI: 101108.DPM-07-2015-0153.

[42] Meek, J.W. \& Marshall, K.S., Cultivating resiliency through system shock: The southern California metropolitan water management system as a complex adaptive system. Public Management Review, 20, pp. 1088-1104, 2018.

DOI: $10.1080 / 14719037.2017 .1364408$.

[43] Klijn, E.H., Complexity theory and public administration: What is new? Public Management Review, 10, pp. 299-318, 2008. DOI: 10.1080/14719030802002675.

[44] Marion, R. \& Bacon, J., Organizational extinction and complex systems. Emergence, 1(4), pp. 71-96, 2000.

[45] Marion, R., The Edge of Organization: Chaos and Complexity Theories of Formal Social Systems, SAGE: London, 1999.

[46] Inserra, D. et al., After the storms: Lessons from hurricane response and recovery in 2017. Special Report No. 201, Heritage Foundation, Washington, DC. www.heritage.org/sites/default/files/2018-04/SR-201.pdf. Accessed 15 Jul. 2019.

[47] Begun, J.W., Zimmerman, B. \& Dooley, K., Health care organizations as complex adaptive systems. Advances in Health Care Organization Theory, eds S.M. Mick \& M. Wyttenbach, Jossey-Bass: San Francisco, pp. 253-288, 2003. 